\title{
EFSUMB Recommendations and Clinical Guidelines for Intestinal Ultrasound (GIUS) in Inflammatory Bowel Diseases
}

\section{EFSUMB-Empfehlungen und klinische Leitlinien für den gastrointestinalen Ultraschall (GIUS) chronisch entzündlichen Darmerkrankungen (CED)}

Authors

Giovanni Maconi ${ }^{1}$, Kim Nylund ${ }^{2}$, Tomas Ripolles ${ }^{3}$, Emma Calabrese ${ }^{4}$, Klaus Dirks ${ }^{5}$, Christoph F. Dietrich ${ }^{6}$, Alois Hollerweger ${ }^{7}$, Ioan Sporea ${ }^{8}$, Adrian Saftoiu ${ }^{9}$, Christian Maaser ${ }^{10}$, Trygve Hausken ${ }^{11}$, Antony P. Higginson ${ }^{12}$, Dieter Nürnberg ${ }^{13}$, Nadia Pallotta ${ }^{14}$, Laura Romanini ${ }^{15}$, Carla Serra ${ }^{16}$, Odd Helge Gilja ${ }^{17}$

Affiliations

1 Gastroenterology Unit, Department of Biomedical and Clinical Sciences, “L. Sacco” University Hospital, Milan, Italy

2 National Centre for Ultrasound in Gastroenterology, Haukeland University Hospital, Bergen, Norway

3 Radiology, Hospital Universitario Doctor Peset, Valencia, Spain

4 Gastroenterology Unit, Department of Systems Medicine, University of Rome Tor Vergata, Roma, Italy

5 Gastroenterologie und Innere Medizin, Rems-MurrKlinikum Winnenden, Germany

6 Innere Medizin 2, Caritas-Krankenhaus, Bad Mergentheim, Germany

7 Department of Radiology, Hospital Barmherzige Brüder, Salzburg, Austria

8 Department of Gastroenterology and Hepatology, "Victor Babes” University of Medicine and Pharmacy, Timisoara, Romania

9 Research Center of Gastroenterology and Hepatology, University of Medicine and Pharmacy of Craiova, Romania

10 Ambulanzzentrum Gastroenterologie, Klinikum Lüneburg, Germany

11 Department of Medicine, Haukeland University Hospital, Bergen, Norway

12 Department of Radiology, Queen Alexandra Hospital, Portsmouth Hospitals NHS Trust, Portsmouth, United Kingdom of Great Britain and Northern Ireland

13 Gastroenterology, Ruppiner Kliniken, Neuruppin, Germany

14 Department of Internal Medicine and Medical Specialties, Sapienza University of Rome, Roma, Italy

15 Dept.of Radiology, Radiologia 1, Spedali Civili di Brescia, Italy

16 Interventional Ultrasound Unit, Department of Organ Failure and Transplantations, Sant'Orsola-Malpighi Hospital and University of Bologna, Italy

17 National Centre for Ultrasound in Gastroenterology, Haukeland University Hospital, Bergen, and Department of Clinical Medicine, University of Bergen, Norway
Key words

Gastrointestinal tract, inflammatory bowel diseases, guidelines, ultrasound, Crohn's disease, ulcerative colitis, IBD, ultrasonography

received 03.07.2017

accepted 05.12 .2017

Bibliography

DOI https://doi.org/10.1055/s-0043-125329

Published online: March 22, 2018

Ultraschall in Med 2018; 39: 304-317

(c) Georg Thieme Verlag KG, Stuttgart · New York

ISSN 0172-4614

Correspondence

Prof. Giovanni Maconi

Gastroenterology Unit, Department of Biomedical and Clinical Sciences, “L. Sacco” University Hospital, “L. Sacco” University Hospital, Via GB Grassi, 74, 20157 Milan, Italy

Tel.: ++ 39/2/39043164

Fax: ++39/2/3942232

giovanni.maconi@unimi.it

\section{ABSTRACT}

The accuracy and usefulness of gastrointestinal ultrasound (GIUS) for detecting activity and complications of inflammatory bowel diseases (IBD), has been reported in studies, promoting this technique as an important tool for the management of IBD patients. Whilst well recognised by international guidelines, standardization and general agreement in the definition of the luminal and extra-intestinal features, still need to be well defined.

A task force group of 17 experts in GIUS faced this issue, by developing recommendations and clinical guidelines for the use of GIUS in IBD, under the auspices of EFSUMB. This article presents the consensus on the current data on sonographic features of IBD and summarises the accuracy of different sonographic modalities for the management of IBD patients. 


\section{ZUSAMMENFASSUNG}

Über die Genauigkeit und den Nutzen des gastrointestinalen Ultraschalls (GIUS) zum Nachweis von Aktivität und Komplikationen bei entzündlichen Darmerkrankungen (IBD „inflammatory bowel disease“) wurde in Studien berichtet, die diese Technik als wichtige Methode beim Management von IBD-Patienten propagieren. Die Standardisierung und der allgemeine Konsens bei der Definition der luminalen und extra-intestinalen Merkmale ist zwar von internationalen Leitlinien aner- kannt, muss aber noch genau definiert werden. Eine Arbeitsgruppe von 17 GIUS-Experten hat sich diesem Problem angenommen und entwickelte unter der Schirmherrschaft des EFSUMB Empfehlungen und klinische Leitlinien für den Einsatz von GIUS bei IBD. Dieser Artikel präsentiert den Konsens über die sonografischen Merkmale bei IBD aufgrund der aktuellen Datenlage und fasst die Genauigkeit verschiedener sonografischer Verfahren für das Management von IBD-Patienten zusammen.

\section{Introduction}

Crohn's disease (CD) and ulcerative colitis (UC) are chronic inflammatory bowel diseases (IBD) with increasing incidence and prevalence worldwide [1]. The onset of IBD may occur in different decades of life with CD being more frequent in the second and third decade. Many patients are still faced with a diagnostic delay [2, 3].

\section{Diagnostic imaging in the management of IBD}

IBD patients need clinical, biochemical, endoscopic, and crosssectional assessment to confirm the diagnosis and flares of the disease, to detect complications and to guide treatment. To date, endoscopy remains the main diagnostic procedure since it allows biopsy and histological evaluation [4]. However, it has limitations with respect to the assessment of the complications and proximal ileal extension of CD [5]. Furthermore, European guidelines on diagnostics in IBD have recommended complementary imaging methods, such as gastrointestinal ultrasound (GIUS), computed tomography enterography (CTE) and magnetic resonance enterography (MRE) for the diagnosis and determination of the location, extent and complications of CD [6].

\section{Gastrointestinal ultrasound and other imaging tools in IBD}

Systematic reviews and meta-analyses have shown that GIUS, CTE and MRE have comparable diagnostic accuracy for the initial assessment of $C D$, the monitoring of disease activity and progression, and for assessing its main complications (stenoses, fistulae and abscesses) [7 - 10] The latest consensus guidelines by the European Crohn's and Colitis Organization (ECCO) and European Society of Gastrointestinal Radiology (ESGAR) for imaging in IBD have recommended GIUS, CTE, or MRE to detect small bowel CD at its first presentation, to assess disease activity of the terminal ileum, to diagnose stenoses of the small bowel and to assess penetrating complications [11]. Among these techniques, GIUS has the advantage of being well-tolerated, radiation-free, repeatable, generally available and less expensive [12].

\section{Advantages and limitations of GIUS}

The increasing worldwide interest in GIUS for IBD has been recently pointed out [12-14], but issues need to be faced before widespread use, such as standardization and general agreement regarding the definition of the intestinal and extra-intestinal fea- tures, and the criteria for the detection of IBD, which are still not well defined. Indeed the sensitivity and specificity of the technique may vary according to the criteria and cut-offs used [7, 8, 15-19].

For this reason our international team of GIUS experts, under the umbrella of the European Federation of Societies for Ultrasound in Medicine and Biology (EFSUMB), cooperated in order to establish GIUS recommendations for assessing IBD.

\section{Methodological structure and classification of the consensus levels}

The creation of the Task Force Group (TGF) of GIUS experts, the development of guidelines according to a modified Delphi method and all steps that have led to the statements regarding the definition criteria and landmarks of the US features of IBD, with their Level of Evidence (LoE) and Grade of Recommendation (GoR) [20] have been reported in detail in the online version of this issue. All statements in this issue include an agreement/disagreement level that has been scored on a five-point Likert scale as follows: A+: agree; A-: rather agree; I: indecisive; D-: rather disagree; $\mathrm{D}+$ : disagree.

\section{RECOMMENDATION}

1. GIUS is recommended to be used to detect IBD at its first presentation, and to assess CD location, activity and possible complications [LoE 1a, GoR A]. Consensus levels of agreement: $A+17 / 17$;

\section{Features of Crohn's disease}

Crohn's disease, especially when located in the small bowel, can be difficult to detect and challenging to follow-up, since it presents with both intestinal and extra-intestinal features. Transabdominal GIUS can assess luminal, parietal and extra-parietal features of CD and allows the detection and assessment of its severity.

\section{Luminal and parietal features}

\section{Thickening}

Bowel wall thickening (BWT) is by far the most important and most used parameter when diagnosing $C D$, and it is the most consistently used parameter in systematic reviews and meta-analyses 
to detect the disease $[7,8]$. Indeed, BWT is also a reproducible parameter between investigators [21]. We recommend measuring wall thickness in the anterior wall of the bowel (or where it is better visible) in the longitudinal direction, avoiding haustrations and mucosal folds. The cursor/calipers should be placed at the end of the interface echo between the serosa and the proper muscle to the start of the interface echo between the lumen and the mucosa $[22,23]$.

The cut-off for the detection of CD varies among studies. However, the latest meta-analysis, which included 15 prospective studies, showed that a cut-off value of $3 \mathrm{~mm}$ had a sensitivity and specificity of $89 \%$ and $96 \%$, respectively, while other cut-off values ( $4 \mathrm{~mm}$ or more) yielded a sensitivity of $87 \%$ and a specificity of $98 \%$ [16]. Moreover, this study also showed that increased BWT is the best parameter to detect CD located in the small bowel.

The thickening of each single layer of the bowel wall and its clinical significance in CD have been poorly investigated so far. It seems that the proper muscle layer and submucosal layer are thicker in patients with poor response to medical treatment and higher risk of surgery [24, 25] and that the increased thickening of the submucosa is associated with active CD [26]. Overall the degree of BWT is correlated with clinical and biochemical activity of $C D$, but the correlation is weak [27 - 30]. The increased BWT is also the most common parameter to detect $C D$ recurrence after surgery and its degree seems to be correlated with the severity of endoscopic recurrence (see below).

Furthermore, improvement or even normalization of BWT after immunosuppressive treatment takes a long time and occurs only in a small percentage of patients [27, 31 -33]. Conversely, the lack of improvement or the increase of BWT after treatment is correlated with high risk of surgery [33, 34].

\section{RECOMMENDATIONS}

2. Bowel wall thickening measured by GIUS can be used to accurately evaluate Crohn's disease, in particular when located in the small bowel [LoE 1a, GoR A].

Consensus levels of agreement: A+14/17; A- 2/17; I 1/17

3. Bowel wall thickening $>3 \mathrm{~mm}$ as measured with GIUS should be used as a cut-off for the detection of Crohn's disease when a high sensitivity is preferred while bowel wall thickening $>4 \mathrm{~mm}$ should be used when a high specificity is preferred [LoE 1a, GoR A].

Consensus levels of agreement: A+15/17; A- 1/17; D- 1/17

4. Clinical disease activity in Crohn's disease is correlated with bowel wall thickness and can be estimated using GIUS [LoE 2b, GoR A].

Consensus levels of agreement: A+14/17; A- 1/17; D- 2/17

\section{Echo pattern}

The bowel wall echo pattern may have variable features in $C D$. The wall layers may be intact and all clearly visible with preserved stratification but may also be focally or extensively disrupted (disrupted or hypoechoic echo pattern). The diseased bowel may also show tracts with preserved stratification alternating with a disrupted echo pattern.

Changes in the predominance of the layers or loss of stratification may be related to different disease aspects [26, 35, 36]. The loss of mural stratification (the disrupted or hypoechoic echo pattern) correlates with clinical and biochemical CD activity [27, 37, 38] with prevalent histological inflammation [39] and with increased risk of surgery [40-42]. In vitro studies revealed that the focal disappearance sign or focal destruction of wall stratification is caused by deep longitudinal ulcerations [43 - 45].

\section{RECOMMENDATIONS}

5. GIUS can demonstrate preserved or disrupted stratification of a thickened bowel wall in Crohn's disease [LoE 4, GoR C] Consensus levels of agreement: A+16/17; A- 1/17

6. The focal or extensive disruption of bowel wall layers can be detected by GIUS and suggests severe disease, possibly with ulcerations [LoE 4, GoR C]

Consensus levels of agreement: $A+15 / 16$; A- 1/16

7. Increased bowel wall thickening and loss of stratification as detected by GIUS suggest a higher risk of surgery in patients with Crohn's disease [LoE 4, GoR C] Consensus levels of agreement: A+15/17; A- 1/17; D- 1/17

\section{Vascularity}

\section{Splanchnic vascularity in CD}

Crohn's disease affects the in- and outflow of splanchnic vessels that can be assessed using pulse wave Doppler. Clinical disease activity, namely disease activity established by clinical indices such as Crohn's Disease Activity Index (CDAl) or Harvey Bradshow Index $(\mathrm{HBI})$, is associated with increased flow in the mesenteric and portal vein or mesenteric arteries, either shown as increased maximum velocity, time-averaged mean velocity, flow volume or reduced resistive index in fasting patients in some studies [46 - 52], but with more controversial results in other studies [52-54]. Studies have also compared Doppler US of mesenteric blood flow with endoscopic activity of CD or a combination of clinical, endoscopic and radiological findings with conflicting results [55-58].

The rather disappointing results indicated by measuring flow parameters in splanchnic vessels are probably related to the extensive physiological variability in the flow, also well-known in the healthy population $[59,60]$. Furthermore the intra-subject, inter-observer and inter-equipment variability of color Doppler imaging (CDI) measurements are well documented [61 -63].

\section{RECOMMENDATION}

8. Doppler US of the large mesenteric vessels is not routinely recommended for estimation of disease activity in IBD [ $\mathrm{LoE}$ 4, GoR B] Consensus levels of agreement: $A+17 / 17$ 


\section{Color Doppler assessment of bowel wall in CD}

A more focused approach on $C D$ is the measurement of the vascularity in the affected bowel wall. Bowel wall vascularity can be determined at the level of the most thickened segments, by color or power Doppler US, using special presets optimized for slow flow detection [23]. Color Doppler flow is usually semi-quantitative and graded subjectively. There are scoring systems assessing the degree of vascularity based on thickening of the bowel wall coupled with the number, size and extent of the power Doppler signals [64, 65].

This subjective assessment of vascularity seems to reflect vessel density and inflammatory activity in the histologically examined bowel wall [66-69]. Furthermore, bowel wall vascularity seems to be correlated with endoscopic activity [67, 69-71] and clinical activity (e. g., Harvey-Bradshaw index score of $\geq 4$ or Crohn's disease activity index $\geq 150)[27,33,58,68,71-75]$ and to a lesser degree with biochemical activity (e. g., C-reactive protein or fecal calprotectin) of CD [58]. Moreover, persistence of increased vascularity despite clinical remission after treatment may suggest an increased risk of relapse [74].

\section{RECOMMENDATION}

9. Semi-quantitative assessment of bowel wall vascularity using color Doppler techniques is useful to evaluate Crohn's disease activity [LoE 2b, GoR B] Consensus levels of agreement: A+16/17; A- 1/17

\section{Contrast-enhanced US assessment of bowel wall in CD}

Despite the capabilities of US color Doppler to suggest CD activity, its accuracy in detecting slow-moving blood flow in small vessels and vascularity in deep-lying bowel wall segments is low. Contrast-enhanced ultrasound (CEUS) overcomes these limitations, improving the detection of hypervascularity and perfusion, also in the deep-seated bowel wall and in the capillaries.

Assessing contrast-enhanced blood flow in the bowel wall is more complex [23]. Studies show considerable heterogeneity with regard to CEUS techniques and contrast parameters to assess bowel wall vascularity in CD [76 - 78]. The main parameters could be simply subdivided into qualitative, semi-quantitative and quantitative. The main qualitative and semi-quantitative parameters include different patterns of contrast enhancement, such as variation of layer enhancement of the bowel wall [79] and patterns of perfusion, such as submucosal enhancement and inward and outward transparietal enhancement [71]. Among the several quantitative parameters investigated, the relative peak enhancement and the area under the curve seem to be most reproducible, reliable and widely used to discriminate disease activity and to assess the histological features of the bowel wall $[25,78,80]$.

Several studies and meta-analyses have shown that CEUS has high accuracy in the detection of active CD using endoscopy or clinical index as the reference standard $[18,19]$. CEUS also seems to provide relevant prognostic information regarding treatment efficacy in patients with $C D$. In fact, improvement of several per- fusion parameters, such as peak contrast enhancement, rate of wash-in and wash-out and, in particular, the area under the time intensity curve of the intestinal wall, 4-6 weeks after starting anti-inflammatory treatment (anti-TNF-alpha), correlated with a favorable response $[25,80]$.

Furthermore, CEUS showed excellent accuracy for the diagnosis of postoperative $C D$ recurrence. In particular, the peak contrast enhancement $>46 \%$ over baseline showed a $10 \%$ increase in accuracy compared with conventional parameters such as BWT $>3 \mathrm{~mm}$ and the assessment of color Doppler flow [81]. Likewise, the pattern of enhancement showed a sensitivity and specificity of $94 \%$ for identifying endoscopic recurrence compared with a modified endoscopic Rutgeerts score [71].

Several studies assessed the accuracy of CEUS for evaluating various aspects of disease activity. The endoscopic activity has been assessed by CEUS using parameters derived by the time enhancement intensity curves, such as maximum peak intensity or relative peak enhancement, showing a sensitivity of $68-100 \%$ and a specificity of $73-96 \%$ for discriminating endoscopically active from inactive disease [70, 82 - 85]. In contrast, the correlation between CEUS and clinical and biochemical activity of CD is more controversial [71, 79, 85-88].

\section{RECOMMENDATIONS}

10. CEUS of the bowel may be used to estimate endoscopic activity in Crohn's disease [LoE 1b, GoR A] Consensus levels of agreement: A+11/16; A- 4/16; D+1/16

11. CEUS methods and parameters for assessing Crohn's disease are heterogeneous and should be kept stable over time when monitoring disease activity [LoE 2b, GoR A] Consensus levels of agreement: A+16/16

\section{Extraintestinal features}

\section{Lymph nodes}

Mesenteric loco-regional lymph nodes are a common finding in healthy subjects, particularly in children [89], and in CD patients. Enlarged inflammatory mesenteric lymph nodes related to CD are usually described at US as oval or elongated with lesser diameter $>5 \mathrm{~mm}$ and seem to be correlated with young age, early disease, or disease with shorter duration, and with the presence of fistulae and abscesses [90-92]. However, enlarged mesenteric lymph nodes do not seem to be strongly correlated with clinical disease activity and also appear in other intestinal disorders [27, 90].

\section{RECOMMENDATION}

12. Regional mesenteric lymphadenopathy is a common but non-specific sonographic finding in early Crohn's disease and can be detected by GIUS [LoE 3b, GoR C] Consensus levels of agreement: A+15/17; A-1/17; D+1/17 


\section{Mesenteric fat hypertrophy}

Mesenteric fat hypertrophy or creeping fat is a common feature of active $C D$. Although it seems to be associated with transmural inflammation, fibrosis, muscular hypertrophy and stricture, its role in the onset and development of CD is not fully understood [93]. Creeping fat appears on US as hyperechoic tissue or "mass effect" encircling the diseased bowel. It is found by US in approximately $40-50 \%$ of CD patients with a reported sensitivity and specificity $>83 \%$ compared to multi-detector CT scan [94-96]. However, this finding is associated with clinical and biochemical disease activity, and it may disappear or improve in patients who have responded to medical treatment $[27,96]$.

\section{RECOMMENDATION}

13. Mesenteric hypertrophy can be detected by GIUS as hyperechoic tissue or "mass effect wrapping" around the diseased bowel and reflects clinical and biochemical disease activity [LoE 3b, GoR C] Consensus levels of agreement: A+15/17; A- 1/17; । 1/17

\section{Abdominal free fluid}

A small amount of free fluid, close to the affected bowel segments, is a common, easily detectable and reproducible US finding in $C D$ patients, but its prevalence and significance have not been fully investigated [21]. However, it seems to be a nonspecific finding, as it can been found in most patients irrespective of their underlying disease [97].

\section{RECOMMENDATION}

14. Free fluid in the abdomen can be detected using GIUS and is an nonspecific finding with no clear significance in Crohn's disease [LoE 4, GoR C] Consensus levels of agreement: A+17/17

\section{Appendiceal involvement}

As $C D$ at its onset may clinically mimic acute appendicitis, the sonographic recognition of these entities is important to avoid unnecessary laparotomies. Primary involvement of the appendix in $C D$ is rare, sonographically indistinguishable from simple acute appendicitis. It is characterized by markedly thickened and hyperemic walls, frequently associated with a thickened terminal ileum and cecum [98-100].

\section{RECOMMENDATION}

15. Appendiceal involvement in Crohn's disease may be observed by GIUS and is commonly seen in combination with involvement of the terminal ileum and cecum [LoE 4, GoR C] Consensus levels of agreement: A+17/17

\section{Complications in Crohn's disease}

The main abdominal complications of $C D$ are stenoses, fistulae and abscesses. These are the main indications for surgical intervention. Surgery is a frequent treatment in the natural history of CD patients [101, 102].

\section{Stenoses}

Stenoses represent the more frequent abdominal complications and the main cause of surgical intervention (70-90\%) and their prevalence increases over the course of the disease [103, 104]. Several US diagnostic criteria for stenosis have been described [105]. However, the main ones are: thickened and stiff bowel wall, narrowing of the lumen (diameter less than $1 \mathrm{~cm}$ ), proximal dilatation (>25-30 mm) and hyperperistalsis of the prestenotic gut $[106,107]$.

The higher diagnostic accuracy of US is obtained when surgery is considered the reference standard. In a systematic review of literature, US has demonstrated a sensitivity for the diagnosis of stenosis from $74 \%$ to $100 \%$, with a specificity in the range of $89 \%$ to $93 \%[8,10,12,106-110]$. Irrespective of the gold standard used, $X$-ray or intraoperative findings, the ingestion of an oral contrast agent such as polyethylene glycol (PEG) solution $(500-800 \mathrm{ml})$ drunk approximately 30 minutes before the US examination [also called Small Intestine Contrast US (SICUS)] has been shown to improve the sensitivity of US for identifying patients with at least 1 stenosis (74\% vs. $89-98 \%$ ) and those with 2 or more strictures (55\% vs. $75-77 \%$ ) with an overall good specificity (>93\%) [109, 111]. Moreover, there is a good correlation between the extent of small bowel strictures measured by means of US and X-ray, and between the extent of the disease measured at surgery $[109,112]$.

Stenoses in CD are often the result of a combination of fibrosis and inflammation, although they are usually classified as predominantly inflammatory or fibrotic. Patients with strictures with prominent inflammation can potentially be managed with medical treatment, whereas patients with narrowed bowel segments and with prevalent fibrosis, in particular if associated with obstructive symptoms, frequently require endoscopic dilatation or surgery [113]. Despite the fact that this issue is much more complicated and likely also involves smooth muscle hyperplasia/ hypertrophy that may be correlated with chronic inflammation [114], the US pattern of the bowel wall can help to differentiate between inflammatory and fibrotic stenosis. The hypoechoic pattern is more typical of inflammatory stenosis, while the stratified or nonhomogeneous echo pattern indicates fibrosis [24, 39]. Several studies have shown that the degree of vascularization and hyperemia on color Doppler and CEUS is correlated with the histologically proven degree of inflammation [24, 105, 115]. In particular, CEUS is useful for distinguishing inflammatory from fibrostenotic lesions in CD. Most studies showed that the contrast enhancement of the bowel wall of inflammatory strictures (using surgical pathological specimens as the reference standard) is significantly greater compared to that of fibrotic strictures [24, 82, $116-119]$. 
Recent studies reported a significant correlation between the measurement of transabdominal bowel wall stiffness assessed by sonoelastography and the degree of bowel fibrosis at histology $[118,120-123]$.

\section{RECOMMENDATIONS}

16. Stenoses can be visualized by GIUS as segments of bowel wall thickening with luminal narrowing and pre-stenotic dilatation [EL 2a, GoR A].

Consensus levels of agreement: $A+16 / 17 ;$ । 1/17

17. Oral contrast agents may be applied to increase the accuracy of GIUS to diagnose patients with Crohn's stenoses, particularly those with multiple stenoses [EL 2a, GoR A]. Consensus levels of agreement: A+16/17; A- 1/17

18. a. Loss of stratification, hyperemia on color Doppler US or CEUS of the bowel wall, at the level of the stricture, suggest its inflammatory nature.

b. Stratification or hypovascularization of the bowel wall, at the level of the stricture, suggests a higher degree of fibrosis [EL 2a, GoR A].

Consensus levels of agreement: A+14/16; A- 1/16; I 1/16

19. GIUS with elastography may be applied to evaluate the stiffness of a Crohn's stenosis [EL 2b, GoR B]

Consensus levels of agreement: $A+11 / 15 ; A-2 / 15 ; \mid$ 2/15

\section{Intestinal fistulae}

Fistulae, sinus tracts and fissures are hallmarks of CD and lead to peri-intestinal abscesses, loop adhesions and stricture formation. Extramural fissures originating from deep ulcerations of the intestinal wall are visualized as subtle hypoechoic irregularities of the bowel surface, in correspondence with hypoechoic segments of the bowel wall. Fissures result in the formation of sinus tracts and fistulae. Sinus tracts are linear extensions of inflammation that may have a blind end or finish in an inflammatory mesenteric mass [94, 124-128].

Abdominal fistulae in CD are classified as internal and external. The internal can be entero-enteric, entero-mesenteric or enterovesical [129]. The US diagnostic criteria of sinus tracts and fistulae are similar and include: hypoechoic areas or tracts between ileal loops with or without internal gaseous artifacts; hypoechoic periintestinal tracts with or without gas within; hypoechoic peri-intestinal areas with a diameter $<2 \mathrm{~cm}[107-110,129-133]$. The sensitivity of US for the diagnosis of fistulizing lesions ranged from $67 \%$ to $87 \%$, with a specificity in the range of $90 \%$ to $100 \%$ [8], similar to $C T$ and MR. The latest consensus guidelines by the ECCO and ESGAR for imaging in IBD have recommended GIUS as one of the diagnostic procedures to assess perforating complications [11].

\section{RECOMMENDATIONS}

20. Fistulae in Crohn's disease can be identified by GIUS as hypoechoic tracts with or without air bubbles [LoE 2b, GoR A] Consensus levels of agreement: A+17/17

21. GIUS can be applied with high sensitivity and specificity, comparable to $\mathrm{CT}$ or MRI, for the detection of $\mathrm{CD}$ fistulas [LoE 1; GoR A]

Consensus levels of agreement: A+14/17; A- 3/17

\section{Abdominal abscesses}

In $12-30 \%$ of CD patients, an abscess occurs as a result of a fistula or surgical intervention. The US appearance is characterized by: hypo-anechoic lesions containing fluid and gaseous artifacts; posterior enhancement; irregular margins sometimes within hypertrophic mesentery [107-110, 129-132, 134].

The sensitivity of US for the diagnosis of abdominal abscesses ranges from $81 \%$ to $100 \%$, with a specificity in the range of $92 \%$ to $94 \%$ [8], similar to CT and MR, although certain anatomic areas, such as the deep pelvis and left hypochondrium, are difficult to assess by GIUS and lesions can be missed. Abscesses and inflammatory masses or phlegmons can have a similar appearance on conventional US. This limit can be overcome using CEUS [135]. CEUS can demonstrate diffusely increased enhancement in phlegmons, while abscesses enhance only in the peripheral zone, with an avascular central portion, due to the fluid collection. To minimize radiation exposure, US should be preferred over CT for the detection of complications [8, 12]. Particularly, it is useful to monitor $C D$ patients under treatment with biologic agents, which are contraindicated in patients with intra-abdominal abscesses, but may be effective in those with phlegmons [136].

\section{RECOMMENDATIONS}

22. Abscesses can be detected using GIUS as organized fluid collections that may contain bubbles of gas [LoE 2a, GoR B] Consensus levels of agreement: $A+17 / 17$

23. CEUS is useful for distinguishing between phlegmons and abscesses [LoE 2a, GoR B]

Consensus levels of agreement: A+17/17

24. GIUS may be applied with high sensitivity and specificity to detect Crohn's abscesses [LoE 2, GoR B] Consensus levels of agreement: $A+17 / 17$

\section{Postoperative recurrence in Crohn's disease}

Despite advancement in medical therapy, surgery is still required in more than half of CD patients and reoperation in up to $60 \%$ of these patients [137]. The identification of predictive factors of recurrence and ileo-colonoscopic assessment of postoperative 
recurrence (Rutgeerts score) within the first year after surgery are crucial to optimize therapeutic management [138].

Several studies and systematic reviews have assessed the role of bowel US in postoperative follow-up, showing that the detection of increased bowel wall thickening $>3 \mathrm{~mm}$ of the anastomosis or neoterminal ileum is an accurate indicator for recurrence, with a sensitivity $>80 \%$ and specificity $>88 \%[8,12]$. In this regard, prospective studies have shown that the use of PEG solution (SICUS) [139 - 143] and color Doppler or CEUS [81, 144] can increase the sensitivity up to $90-98 \%$, albeit with a decrease in specificity. This is valid for US assessment performed 1 year after surgery. With shorter follow-up, e. g. 3 months, the sensitivity of US in assessing and predicting postoperative recurrence appears inaccurate $[141,145]$.

Moreover, both GIUS and SICUS, adopting different cut-off levels for bowel thickness ( $>5 \mathrm{~mm}$ for conventional sonography and $>4 \mathrm{~mm}$ for SICUS), can suggest severe endoscopic postoperative recurrence and accordingly could replace endoscopy in the postsurgical follow-up [146]. In CD patients treated with conservative surgery (e. g. stricturoplastics or minimal bowel resections), GIUS is useful to monitor the postoperative behavior of bowel wall thickness and provides prognostic information. US detection of unchanged or worsened wall thickness 6 months after surgery or the postoperative persistence of wall thickness $>6 \mathrm{~mm}$ is predictive of a high risk of recurrence $[147,148]$.

\section{RECOMMENDATIONS}

25. Postoperative recurrence can be accurately detected using GIUS by assessing the thickness of ileo-colonic anastomosis or neo-terminal ileum $(>3 \mathrm{~mm}) 1$ year after surgery [LoE 1b GoR A] Consensus levels of agreement: A+16/17; A- 1/17

26. Doppler US and CEUS assessment of thickened neo-terminal ileum and the use of oral contrast agents can improve the sensitivity of postoperative detection of recurrence [LoE 1b GoR A] Consensus levels of agreement: A+14/17; A- 2/17; D+1/17

\section{Sonographic scores in Crohn's disease}

The various US mural and extramural features of CD may have relevant prognostic implications and have been used to build sonographic indexes. The US detection of bowel wall thickness $>7 \mathrm{~mm}$ has been shown to be an independent risk of surgery (OR $=19.5,95 \% \mathrm{Cl}: 5.362-71.065)$ [34]. The short-term risk of surgery has also been evaluated with a score that included weighted parameters such as: wall thickness (> $4.5 \mathrm{~mm})$, wall echo pattern ("disrupted stratification") and presence of fistulae/ abscesses and stenoses. Although not validated, this score was able to correctly identify up to $84 \%$ of patients requiring shortterm surgery [40]. Following this trend, a numerical index, quantitating small bowel damage as detected by SICUS in CD patients, has been developed more recently with the aim of converting qualitative sonographic images into a numerical index for $C D$
(Sonographic Lesion Index for CD - SLIC). Also this index was able to identify patients with higher lesion indices who underwent surgery more frequently than those with lower indices after oneyear follow-up [149], and can be used to monitor changes in transmural bowel damage during anti-TNF therapy for CD [150]. An attempt to develop an ultrasonographic index of inflammatory activity for $C D$ was proposed on the basis of wall thickness and wall stratification of the gut, subdivided into eight segments. The results of this index showed a correlation $\left(r^{2}=0.62, P<0.01\right)$ with endoscopic/radiological score, but, given its complexity and lack of validation, it has remained unused [38].

\section{RECOMMENDATION}

27. Indexes and scores using GIUS may be a tool for predicting the risk of surgery and quantifying bowel damage [LoR 4 GoR C] Consensus levels of agreement: A+14/16; A- 2/16

\section{Ulcerative colitis}

Ulcerative colitis, unlike $C D$, involves only the colonic mucosa starting from the rectum (proctitis) often ascending to the rest of the colon. Nowadays, colonoscopy is the method of choice and the reference standard in UC $[151,152]$. Intestinal US is an accurate tool to detect and assess the extension of active UC and to define disease activity. The typical grayscale US finding in active UC is moderate thickening of the intestinal wall (usually below $9 \mathrm{~mm}$ ), involving the mucosa and submucosa, sometimes with increased echogenicity of the submucosal layer, without involvement of the proper muscle layer or surrounding fat. Typical findings may be the irregular mucosal surface caused by gas bubbles entrapped among pseudopolyps and in deep ulcerations and the loss of haustration [153]. Because the lesions in UC are not transmural, the colonic wall stratification is usually preserved [154], although it may be disrupted in patients with severe activity. In particular, the diagnosis of ulcerative colitis relies in most studies on the detection of bowel wall thickness $>4 \mathrm{~mm}$ in adults [153 - 156] and $>3 \mathrm{~mm}$ in children [157 - 159]. Intestinal US can be used to assess UC extension, but is more challenging for rectal involvement, where the sensitivity is approximately $15 \%$. For the remaining colon the sensitivity is higher than $70 \%$, i. e., up to $97 \%$ for the sigmoid and descending colon [156].

Wall thickness correlates well with clinical activity $[153,158-$ 164], with biological tests like C-reactive protein values [155, 159, $163]$ and also with endoscopy findings [153, 155, 158, 163, 164]. Loss of bowel wall stratification (hypoechoic pattern) was associated with moderate (55\% of cases) and severe forms ( $100 \%$ of cases) [165], while normal wall stratification was present in $87 \%$ of mild cases in another study [166]. Increased vascularity assessed by Doppler US of the bowel wall (increased Doppler signals with low resistance) was also associated with both clinical and endoscopic activity of UC $[158,159,166,168]$. Attempts have been made to establish an ultrasonic activity score. One of these, 
based on extension and degree of colonic wall thickness, showed that it is possible to discriminate severe and moderately severe attacks with a sensitivity of $90 \%$ and a specificity of $96 \%$ [160], but it was not validated due to a lack of large cohort studies.

Transabdominal US can also be used for the assessment of UC response to treatment by assessing wall thickness [160, 163, 169, $170]$, and vascularity changes by CEUS [171, 172]. Regarding response to treatment, published data are contradictory. One study concluded that color and power Doppler are useful [173], while another showed no correlation [172]. Furthermore, CEUS quantification can be used for noninvasive assessment of activity in UC $[172,174]$ and for treatment response $[171,172]$. Strain elastography of the colonic wall may provide information that correlates with endoscopic and clinical disease activity [175].

Appendiceal involvement is seen in $15 \%$ to $86 \%$ of patients with $\mathrm{UC}$ and is more common in proctosigmoiditis, than in more extensive UC. It seems to be related to a better response to therapy and higher risk of pouchitis after ileo-colic anastomosis [152, 176].

\section{RECOMMENDATIONS}

28. GIUS can be used to estimate long segment thickening of the colonic wall, usually present in active UC [ LoE 1b GoR A] Consensus levels of agreement: A+17/17

29. In active ulcerative colitis the echo-stratification that can be visualized using GIUS may be preserved, except in severe disease. The thickening involves the mucosa and submucosal layer [LoE 1b GoR B] Consensus levels of agreement: $A+17 / 17$

30. Increased Doppler signals in the thickened bowel wall that can be observed using GIUS should be interpreted as a sign of active inflammation [LoE $1 b$ GoR B] Consensus levels of agreement: A+16/17; A-1/17

31. CEUS highlights the inflammatory hypervascularity of the bowel wall and it can be used to evaluate therapy response [LoE 2b GoR B] Consensus levels of agreement: A+15/17; A-1/17; I 1/17

32. GIUS can be used to differentiate between UC and $C D$ based on the location of the disease, degree of wall thickening, preserved stratification, lack of surrounding fat involvement or penetrating complications [LoE 4 GoR C] Consensus levels of agreement: A+16/17; A- 1/17

\section{Complications of ulcerative colitis}

Ultrasound may detect extra-intestinal complications of UC (e.g., primary sclerosing cholangitis) [177], but findings of intestinal complications have not been validated in prospective studies. Toxic megacolon combines abnormal colonic dilatation $(>6 \mathrm{~cm})$, thin colonic walls $(<2 \mathrm{~mm})$ and fluid-filled bowel $[178,179]$. Massive pseudopolyposis as well as cancer in IBD may show irregular thickening of the wall [180] or a pseudokidney sign. However, GIUS does not play a major role in diagnosing these complications. Portomesenteric vein thrombosis may be detected by color Doppler imaging and CEUS in up to $26 \%$ of acute or quiescent IBD patients $[76,181,182]$.

\section{RECOMMENDATION}

33. Intestinal complications of UC, like toxic megacolon, may show some specific features that can be observed by GIUS [LoE 4 GoR B] Consensus levels of agreement: A+15/16; D- 1/16

\section{Differential diagnosis among inflammatory colitides}

GIUS has limited value compared to histology in differentiating various enterocolitides. However, GIUS assessment of the area of gut involvement and of mural and transmural changes of the bowel and vascularity may help to differentiate CD from UC [36, 156, 183-186], and other infectious (e.g. tuberculous, bacterial, pseudomembranous and parasitic) [187 - 191], vascular and inflammatory enterocolitides (e. g. ischemic, NSAID, HenochSchönlein purpura) [192-196] and to suggest the nature of lesions in most patients [166, $197-199]$.

\section{RECOMMENDATION}

34. GIUS detection of specific features of the bowel, mainly the site of bowel involvement and peri-intestinal signs, can be used to differentiate Crohn's disease from ulcerative colitis and other intestinal conditions [LoE 4 GoR C] Consensus levels of agreement: A+14/16; A- 1/16; I 1/16

\section{Conflict of Interest}

These authors declare a possible conflicts of interest: GM: Abbvie, Janssen, Alfa-Sigma Novartis, Allergan, THD, Takeda. KN: AbbVie, Ferring, Meda AS. IS: GE, Philips, Siemens, Abbvie, Bristol Myers Squibb. APH: Toshiba. CFD: Bracco, Hitachi, GE, Mindray, Supersonic, Pentax, Covidien, Boston Scientific, AbbVie, MSD, Falk Foundation, Novartis, Roche, Siemens, Olympus, Fuji. OHG: Abbvie, Bracco, Almirall, GE, Takeda AS, Meda AS, Ferring, Allergan, Samsung. CS: Bracco. DN Falk Foundation. $A S, A H, T R, N P, K D, T H, L R, E C, C M$ no COI.

\section{Acknowledgments}

The authors thank Prof. Giovanni Casazza, MD, PhD, from Epidemiology and Biostatistic Unit - Department of Biomedical and Clinical Sciences, “L.Sacco" University Hospital - Milan. 


\section{References}

[1] Molodecky NA, Soon IS, Rabi DM et al. Increasing incidence and prevalence of the inflammatory bowel diseases with time, based on systematic review. Gastroenterology 2012; 142: 46-54.e42

[2] Schoepfer AM, Dehlavi MA, Fournier N et al. Diagnostic delay in Crohn's disease is associated with a complicated disease course and increased operation rate. Am J Gastroenterol 2013; 108: 1744-53

[3] Ott C, Obermeier F, Thieler $S$ et al. The incidence of inflammatory bowel disease in a rural region of Southern Germany: a prospective populationbased study. Eur J Gastroenterol Hepatol 2008; 20: 917-23

[4] Annese V, Daperno M, Rutter MD. European Crohn's and Colitis Organisation European evidence based consensus for endoscopy in inflammatory bowel disease. J Crohns Colitis 2013; 7: 982-1018

[5] Wilkens R, Novak KL, Lebeuf-Taylor E et al. Impact of Intestinal Ultrasound on Classification and Management of Crohn's Disease Patients with Inconclusive Colonoscopy. Can J Gastroenterol Hepatol 2016; 2016: doi:8745972

[6] Gomollón F, Dignass A, Annese V et al. 3rd European Evidence-based Consensus on the Diagnosis and Management of Crohn's Disease 2016: Part 1: Diagnosis and Medical Management. J Crohns Colitis 2017; 11: $3-25$

[7] Horsthuis K, Bipat S, Bennink RJ et al. Inflammatory bowel disease diagnosed with US, MR, scintigraphy, and CT: meta-analysis of prospective studies. Radiology 2008; 247: 64-79

[8] Panés ], Bouzas R, Chaparro M et al. Systematic review: the use of ultrasonography, computed tomography and magnetic resonance imaging for the diagnosis, assessment of activity and abdominal complications of Crohn's disease. Alim Pharmacol Ther 2011; 34: 125-145

[9] Puylaert CA, Tielbeek JA, Bipat S et al. Grading of Crohn's disease activity using CT, MRI, US and scintigraphy: a meta-analysis. Eur Radiol 2015; 25 : 3295-313

[10] Greenup A], Bressler B, Rosenfeld G. Medical Imaging in Small Bowel Crohn's Disease-Computer Tomography Enterography, Magnetic Resonance Enterography, and Ultrasound: "Which One Is the Best for What?" Inflamm Bowel Dis 2016; 22: 1246-61

[11] Panes J, Bouhnik $Y$, Reinisch $W$ et al. Imaging techniques for assessment of inflammatory bowel disease: joint ECCO and ESGAR evidence-based con, sensus guidelines. J Crohns Colitis 2013; 7: 556- 585

[12] Calabrese E, Maaser C, Zorzi F et al. Bowel Ultrasonography in the Management of Crohn's Disease. A Review with Recommendations of an International Panel of Experts. Inflamm Bowel Dis 2016; 22: 1168-83

[13] Asthana AK, Friedman AB, Maconi $G$ et al. Failure of gastroenterologists to apply intestinal ultrasound in inflammatory bowel disease in the AsiaPacific: a need for action. J Gastroenterol Hepatol 2015; 30: 446-452

[14] Atkinson NS, Bryant RV, Dong Y et al. WFUMB Position Paper. Learning Gastrointestinal Ultrasound: Theory and Practice. Ultrasound Med Biol 2016; 42: 2732-42

[15] Fraquelli M, Colli A, Casazza G et al. Role of US in detection of Crohn disease: meta-analysis. Radiology 2005; 236: 95-101

[16] Dong J, Wang $\mathrm{H}$, Zhao J et al. Ultrasound as a diagnostic tool in detecting active Crohn's disease: a meta-analysis of prospective studies. Eur Radiol 2014; $24: 26-33$

[17] Zhu C, Ma X, Xue L, Xu J, Li Q, Wang Y, Zhang J. Small intestine contrast ultrasonography for the detection and assessment of Crohn disease: A meta-analysis. Medicine (Baltimore) 2016; 95 (31): e4235, doi:10.1097/MD.0000000000004235.

[18] Serafin Z, Białecki M, Białecka A et al. Contrast-enhanced Ultrasound for Detection of Crohn's Disease Activity: Systematic Review and Meta-analysis. J Crohns Colitis 2016; 10: 354-62
[19] Ma X, Li Y, jia $\mathrm{H}$ et al. Contrast-enhanced ultrasound in the diagnosis of patients suspected of having active Crohn's disease: meta-analysis. UItrasound Med Biol 2015; 41: 659-68

[20] Howick ], Chalmers I, Glasziou P et al. The Oxford Levels of Evidence 2. OCEBM Levels of Evidence Working Group, Oxford Centre for EvidenceBased Medicine. Available from: 2009 http://www.cebm.net/index. aspx?o=5653

[21] Fraquelli M, Sarno A, Girelli C et al. Reproducibility of bowel ultrasonography in the evaluation of Crohn's disease. Dig Liver Dis 2008; 40: 860 866

[22] Nylund K, Hausken T, Odegaard S et al. Gastrointestinal wall thickness measured with transabdominal ultrasonography and its relationship to demographic factors in healthy subjects. Ultraschall in Med 2012; 33: E225-E232

[23] Nylund K, Maconi G, Hollerweger A et al. EFSUMB Recommendations and Guidelines for Gastrointestinal Ultrasound - Part 1: Examination Techniques and Normal Findings (Short version). Ultraschall in Med 2017; 38: $273-284$

[24] Nylund K, Jirik R, Mezl M et al. Quantitative contrast-enhanced ultrasound comparison between inflammatory and fibrotic lesions in patients with Crohn's disease. Ultrasound Med Biol 2013; 39: 1197-1206

[25] Saevik F, Nylund K, Hausken T et al. Bowel perfusion measured with dynamic contrast-enhanced ultrasound predicts treatment outcome in patients with Crohn's disease. Inflammatory bowel diseases 2014; 20: 2029-2037

[26] Ellrichmann M, Wietzke-Braun P, Dhar S et al. Endoscopic ultrasound of the colon for the differentiation of Crohn's disease and ulcerative colitis in comparison with healthy controls. Alim Pharmacol Ther 2014; 39: $823-833$

[27] Kucharzik T, Wittig BM, Helwig U et al. Use of Intestinal Ultrasound to Monitor Crohn's Disease Activity. Clin Gastroenterol Hepatol 2016; pii: S1542-S3565 (16)31058-8

[28] Maconi G, Parente F, Bollani S et al. Abdominal ultrasound in the assessment of extent and activity of Crohn's disease: clinical significance and implication of bowel wall thickening. Am J Gastroenterol 1996; 91: $1604-1609$

[29] Mayer D, Reinshagen M, Mason RA et al. Sonographic measurement of thickened bowel wall segments as a quantitative parameter for activity in inflammatory bowel disease. Z Gastroenterol 2000; 38: 295-300

[30] Hirche TO, Russler J, Schroder $O$ et al. The value of routinely performed ultrasonography in patients with Crohn disease. Scand J Gastroenterol 2002; 37: $1178-1183$

[31] Castiglione F, Testa A, Rea M et al. Transmural healing evaluated by bowel sonography in patients with Crohn's disease on maintenance treatment with biologics. Inflamm Bowel Dis 2013; 19: 1928-1934

[32] Civitelli F, Nuti F, Oliva S et al. Looking Beyond Mucosal Healing: Effect of Biologic Therapy on Transmural Healing in Pediatric Crohn's Disease. Inflamm Bowel Dis 2016; 22: 2418-2424

[33] Ripollés T, Paredes JM, Martínez-Pérez M] et al. Ultrasonographic Changes at 12 Weeks of Anti-TNF Drugs Predict 1-year Sonographic Response and Clinical Outcome in Crohn's Disease: A Multicenter Study. Inflamm Bowel Dis 2016; 22: 2465 - 2473

[34] Castiglione F, de Sio I, Cozzolino A et al. Bowel wall thickness at abdominal ultrasound and the one-year-risk of surgery in patients with Crohn's disease. Am J Gastroenterol 2004; 99: 1977-1983

[35] Limberg B. Sonographic features of colonic Crohn's disease: comparison of in vivo and in vitro studies. J Clini Ultrasound 1990; 18: 161-166

[36] Limberg B, Osswald B. Diagnosis and differential diagnosis of ulcerative colitis and Crohn's disease by hydrocolonic sonography. Am J Gastroenterol 1994; 89: 1051 - 1057

[37] Bozkurt T, Rommel T, Stabenow-Lohbauer U et al. Sonographic bowel wall morphology correlates with clinical and endoscopic activity in Crohn's disease and ulcerative colitis. Eur J Ultrasound 1996; 4: 27-33 
[38] Futagami Y, Haruma K, Hata J et al. Development and validation of an ultrasonographic activity index of Crohn's disease. Eur J Gastroenterol Hepatol 1999; 11: 1007-1012

[39] Maconi G, Carsana L, Fociani P et al. Small bowel stenosis in Crohn's disease: clinical, biochemical and ultrasonographic evaluation of histological features. Alim Pharmacol Ther 2003; 18: 749-756

[40] Rigazio C, Ercole E, Laudi C et al. Abdominal bowel ultrasound can predict the risk of surgery in Crohn's disease: proposal of an ultrasonographic score. Scand J Gastroenterol 2009; 44: 585-593

[41] Kunihiro K, Hata J, Manabe N et al. Predicting the need for surgery in Crohn's disease with contrast harmonic ultrasound. Scand J Gastroenterol 2007; 42: $577-585$

[42] Rosenbaum DG, Conrad MA, Biko DM et al. Ultrasound and MRI predictors of surgical bowel resection in pediatric Crohn disease. Pediatr Radiol 2017; 47: $55-64$

[43] Hata J, Haruma K, Yamanaka H et al. Ultrasonographic evaluation of the bowel wall in inflammatory bowel disease: comparison of in vivo and in vitro studies. Abdom Imaging 1994; 19: 395 - 399

[44] Kunihiro K, Hata J, Haruma K et al. Sonographic detection of longitudinal ulcers in Crohn disease. Scand J Gastroenterol 2004; 39: 322 - 326

[45] Nylund K, Leh S, Immervoll H et al. Crohn's disease: Comparison of in vitro ultrasonographic images and histology. Scand J Gastroenterol 2008; 43: 719-726

[46] Bolondi L, Gaiani S, Brignola C et al. Changes in splanchnic hemodynamics in inflammatory bowel disease. Non-invasive assessment by Doppler ultrasound flowmetry. . Scand J Gastroenterol 1992; 27: $501-507$

[47] Erden A, Cumhur T, Olcer T. Superior mesenteric artery Doppler waveform changes in response to inflammation of the ileocecal region. Abdom Imaging 1997; 22: $483-486$

[48] Giovagnorio F, Diacinti D, Vernia P. Doppler sonography of the superior mesenteric artery in Crohn's disease. Am J Roentgenol 1998; 170: $123-126$

[49] Mirk P, Palazzoni G, Gimondo P. Doppler sonography of hemodynamic changes of the inferior mesenteric artery in inflammatory bowel disease: preliminary data. Am J Roentgenol 1999; 173: 381 - 387

[50] Yekeler E, Danalioglu A, Movasseghi B et al. Crohn disease activity evaluated by doppler ultrasonography of the superior mesenteric artery and the affected small-bowel segments. J Ultrasound Med 2005; 24: 59-65

[51] Sjekavica I, Barbaric-Babic V, Krznaric Z et al. Assessment of Crohn's disease activity by Doppler ultrasound of superior mesenteric artery and mural arteries in thickened bowel wall: Cross-sectional study. Croatian Med J 2007; 48: $822-830$

[52] Karoui S, Nouira K, Serghini M et al. Assessment of activity of Crohn's disease by Doppler sonography of superior mesenteric artery flow. J Crohns Colitis 2010; 4: 334-340

[53] Maconi G, Imbesi V, Bianchi PorroG. Doppler ultrasound measurement of intestinal blood flow in inflammatory bowel disease. Scand J Gastroenterol 1996; 31: $590-593$

[54] Maconi G, Parente F, Bollani S et al. Factors affecting splanchnic haemodynamics in Crohn's disease: a prospective controlled study using Doppler ultrasound. Gut 1998; 43: 645-650

[55] van Oostayen JA, Wasser MN, Griffioen G et al. Diagnosis of Crohn's ileitis and monitoring of disease activity: value of Doppler ultrasound of superior mesenteric artery flow. Am J Gastroenterol 1998; 93: 88-91

[56] Byrne MF, Farrell MA, Abass S et al. Assessment of Crohn's disease activity by Doppler sonography of the superior mesenteric artery, clinical evaluation and the Crohn's disease activity index: a prospective study. Clin58 Radiol 2001; 56: $973-978$

[57] Ludwig D, Wiener S, Bruning A et al. Mesenteric blood flow is related to disease activity and risk of relapse in Crohn's disease: a prospective follow-up study. Am J Gastroenterol 1999; 94: 2942-2950
[58] Thomson M, Rao P, Berger L et al. Graded compression and power Doppler ultrasonography versus endoscopy to assess paediatric Crohn disease activity pre- and posttreatment. J Pediatr Gastroenterol Nutr 2012; 54: $404-408$

[59] Dietrich CF, Jedrzejczyk M, Ignee A. Sonographic assessment of splanchnic arteries and the bowel wall. Eur J Radiol 2007; 64: $202-212$

[60] Ignee A, Boerner N, Bruening A et al. Duplex sonography of the mesenteric vessels - a critical evaluation of inter observer variability. Z Gastroenterol 2016; 54: $304-311$

[61] Sacerdoti D, Gaiani S, Buonamico P et al. Interobserver and interequipment variability of hepatic, splenic, and renal arterial Doppler resistance indices in normal subjects and patients with cirrhosis. J Hepatol 1997; 27: $986-992$

[62] Zoli M, Merkel C, Sabbà C et al. Interobserver and inter-equipment variability of echo-Doppler sonographic evaluation of the superior mesenteric artery. J Ultrasound Med 1996; 15: 99-106

[63] Sabbà C, Merkel C, Zoli M et al. Interobserver and interequipment variability of echo-Doppler examination of the portal vein: effect of a cooperative training program. Hepatology 1995; 21: 428-433

[64] Limberg B. Diagnosis of chronic inflammatory bowel disease by ultrasonography. Z Gastroenterol 1999; 37: 495-508

[65] Jenssen C, Tuma J, Moller K et al. Ultrasound artifacts and their diagnostic significance in internal medicine and gastroenterology - part 2: color and spectral Doppler artifacts. Z Gastroenterol 2016; 54: 569-578

[66] Sasaki T, Kunisaki R, Kinoshita $\mathrm{H}$ et al. Doppler ultrasound findings correlate with tissue vascularity and inflammation in surgical pathology specimens from patients with small intestinal Crohn's disease. BMC Res Notes 2014; 7: 363

[67] Sasaki T, Kunisaki R, Kinoshita H et al. Use of color Doppler ultrasonography for evaluating vascularity of small intestinal lesions in Crohn's disease: correlation with endoscopic and surgical macroscopic findings. Scand J Gastroenterol 2014; 49: 295-301

[68] Drews BH, Barth TF, Hänle MM et al. Comparison of sonographically measured bowel wall vascularity, histology, and disease activity in Crohn's disease. Eur Radiol 2009; 19: 1379-1386

[69] Epifanio M, Baldisserotto M, Spolidoro JV et al. Grey-scale and colour Doppler sonography in the evaluation of children with suspected bowel inflammation: correlation with colonoscopy and histological findings. Clin Radiol 2008; 63: 968 - 978

[70] Ripollés T, Martínez M], Paredes JM et al. Crohn disease: correlation of findings at contrast-enhanced US with severity at endoscopy. Radiology 2009; 253: $241-248$

[71] Migaleddu V, Scanu AM, Quaia E et al. Contrast-enhanced ultrasonographic evaluation of inflammatory activity in Crohn's disease. Gastroenterology 2009; 137: 43 - 52

[72] Carnevale MaffèG, Brunetti L, Formagnana P et al. Ultrasonographic findings in Crohn's disease. J Ultrasound 2014; 18: 37 - 49

[73] Paredes JM, Ripollés T, Cortés X et al. Abdominal sonographic changes after antibody to tumor necrosis factor (anti-TNF) alpha therapy in Crohn's Disease. Dig Dis Sci 2010; 55: 404-410

[74] Ripollés T, Martínez M], Barrachina MM. Crohn's disease and color Doppler sonography: response to treatment and its relationship with longterm prognosis. J Clin Ultrasound 2008; 36: 267 - 272

[75] Spalinger ], Patriquin H, Miron MC et al. Doppler US in patients with Crohn disease: vessel density in the diseased bowel reflects disease activity. Radiology 2000; 217: 787 - 791

[76] Piscaglia F, Nolsøe C, Dietrich CF et al. The EFSUMB Guidelines and Recommendations on the Clinical Practice of Contrast Enhanced Ultrasound (CEUS): update 2011 on non-hepatic applications. Ultraschall in Med 2012; 33: $33-59$ 
[77] Cheng W, Gao X, Wang W et al. Preliminary Analysis of Clinical Situations Involved in Quantification of Contrast-Enhanced Ultrasound in Crohn's Disease. Ultrasound Med Biol 2016; 42: 1784-1791

[78] Zink F, Kratzer W, Schmidt S et al. Comparison of Two High-End Ultrasound Systems for Contrast-Enhanced Ultrasound Quantification of Mural Microvascularity in Crohn's Disease. Ultraschall in Med 2016; 37: $74-81$

[79] Serra C, Menozzi G, Labate AM et al. Ultrasound assessment of vascularization of the thickened terminal ileum wall in Crohn's disease patients using a low-mechanical index real-time scanning technique with a second generation ultrasound contrast agent. Eur J Radiol 2007; 62: 114-121

[80] Quaia E, Sozzi M, Angileri R et al. Time-Intensity Curves Obtained after Microbubble Injection Can Be Used to Differentiate Responders from Nonresponders among Patients with Clinically Active Crohn Disease after 6 Weeks of Pharmacologic Treatment. Radiology 2016; 281: 606-616

[81] Paredes JM, Ripollés T, Cortés X et al. Contrast-enhanced ultrasonography: usefulness in the assessment of postoperative recurrence of Crohn's disease. J Crohns Colitis 2013; 7: 192-201

[82] Ripolles T, Rausell N, Paredes JM et al. Effectiveness of contrast-enhanced ultrasound for characterisation of intestinal inflammation in Crohn's disease: a comparison with surgical histopathology analysis. J Crohns Colitis 2013; 7: 120-128

[83] Moreno N, Ripolles T, Paredes JM et al. Usefulness of abdominal ultrasonography in the analysis of endoscopic activity in patients with Crohn's disease: changes following treatment with immunomodulators and/or anti-TNF antibodies. J Crohns Colitis 2014; 8: 1079-1087

[84] Horjus TalaburHorje CS, Bruijnen R, Roovers L et al. Contrast Enhanced Abdominal Ultrasound in the Assessment of Ileal Inflammation in Crohn's Disease: A Comparison with MR Enterography. PloS one 2015; 10: e0136105-52

[85] De Franco A, Di Veronica A, Armuzzi A et al. Ileal Crohn disease: mural microvascularity quantified with contrast-enhanced US correlates with disease activity. Radiology 2012; 262: 680-688

[86] Girlich C, Schacherer D, Jung EM et al. Comparison between a clinical activity index (Harvey-Bradshaw-Index), laboratory inflammation markers and quantitative assessment of bowel wall vascularization by contrast-enhanced ultrasound in Crohn's disease. Eur | Radiol 2012; 81: $1105-1109$

[87] Girlich C, Jung EM, Huber E et al. Comparison between preoperative quantitative assessment of bowel wall vascularization by contrast-enhanced ultrasound and operative macroscopic findings and results of histopathological scoring in Crohn's disease. Ultraschall in Med 2011 32: $154-159$

[88] Wong DD, Forbes GM, Zelesco M et al. Crohn's disease activity: Quantitative contrast-enhanced ultrasound assessment. Abdom Imaging 2012; 37: $369-376$

[89] Dietrich CF, Zeuzem S, Caspary WF et al. Sonographische Lymphknotendarstellung im Abdomen bei gesunden Probanden. Ultraschall in Med 1998; 19: 265-269

[90] Maconi G, Di Sabatino A, Ardizzone S et al. Prevalence and clinical significance of sonographic detection of enlarged regional lymph nodes in Crohn's disease. Scand J Gastroenterol 2005; 40: 1328-1333

[91] Dietrich CF, Hocke M, Jenssen C. Ultrasound for abdominal lymphadenopathy. Dtsch Med Wochenschr 2013; 138: 1001-1018

[92] Chiorean L, Barr RG, Braden B et al. Transcutaneous Ultrasound: Elastographic Lymph Node Evaluation. Current Clinical Applications and Literature Review. Ultrasound Med Biol 2016; 42: 16-30

[93] Peyrin-Biroulet L, Chamaillard M, Gonzalez F et al. Mesenteric fat in Crohn's disease: a pathogenetic hallmark or an innocent bystander? Gut 2007; 56: 577-583

[94] Sarrazin J, Wilson SR. Manifestations of Crohn disease at US. Radiographics 1996; 16: 499-520
[95] Gaitini D, Kreitenberg A], Fischer D et al. Color-coded duplex sonography compared to multidetector computed tomography for the diagnosis of crohn disease relapse and complications. J Ultrasound Med 2011; 30: $1691-1699$

[96] Maconi G, Greco S, Duca P et al. Prevalence and clinical significance of sonographic evidence of mesenteric fat alterations in Crohn's disease. Inflamm Bowel Dis 2008; 14: 1555-1561

[97] Smereczynski A, Starzynska T, Kolaczyk K. Ultrasound of selected pathologies of the small intestine. J Ultrasonography 2013; 13: 155-166

[98] Agha FP, Ghahremani GG, Panella JS et al. Appendicitis as the initial manifestation of Crohn's disease: Radiologic features and prognosis. Am J Roentgenol 1987; 149: 515-518

[99] Puylaert JBCM, Van Der Werf SD], Ulrich C et al. Crohn disease of the ileocecal region: US visualization of the appendix. Radiology 1988; 166 : $741-743$

[100] Ripolles T, Martinez MJ, Morote V et al. Appendiceal involvement in Crohn's disease: gray-scale sonography and color Doppler flow features. Am J Roentgenol 2006; 186: 1071-1078

[101] Munkholm P, Langholz E, Davidsen M et al. Intestinal cancer risk and mortality in patients with Crohn's disease. Gastroenterology 1993; 105: $1716-1723$

[102] Bernell O, Lapidus A, Hellers G. Risk factors for surgery and postoperative recurrence in Crohn's disease. Ann Surg 2000; 231: 38 - 45

[103] Cosnes ], Cattan S, Blain A et al. Long-term evolution of disease behaviour of Crohn's disease. Inflamm Bowel Dis 2002; 8: 244-250

[104] Cosnes J, Gower-Rousseau C, Seksik P et al. Epidemiology and natural history of inflammatory bowel diseases. Gastroenterology 2011; 140: $1785-1794$

[105] Coelho R, Ribeiro H, Maconi G. Bowel Thickening in Crohn's Disease: Fibrosis or Inflammation? Diagnostic Ultrasound Imaging Tools. Inflamm Bowel Dis 2017; 23: 23-34

[106] Calabrese E, Zorzi F, Onali S et al. Accuracy of small-intestine contrast ultrasonography, compared with computed tomography enteroclysis, in characterizing lesions in patients with Crohn's disease. Clin Gastroenterol Hepatol 2013; 11: 950-955

[107] Castiglione F, Mainenti PP, De Palma GD et al. Noninvasive diagnosis of small bowel Crohn's disease: direct comparison of bowel sonography and magnetic resonance enterography. Inflamm Bowel Dis 2013; 19: 991- 998

[108] Onali S, Calabrese E, Petruzziello C et al. Small intestine contrast ultrasonography vs computed tomography enteroclysis for assessing ileal Crohn's disease. World J Gastroenterol 2012; 18: 6088-6095

[109] Pallotta N, Vincoli G, Montesani C et al. Small intestine contrast ultrasonography (SICUS) for the detection of small bowel complications in Crohn's disease: a prospective comparative study versus intraoperative findings. Inflamm Bowel Dis 2012; 18: 74-84

[110] Kumar S, Hakim A, Alexakis C et al. Small intestinal contrast ultrasonography for the detection of small bowel complications in Crohn's disease: correlation with intraoperative findings and magnetic resonance enterography. J Gastroenterol Hepatol 2015; 30: 86-91-72

[111] Parente F, Greco S, Molteni M et al. Oral contrast enhanced bowel ultrasonography in the assessment of small intestine Crohn's disease. A prospective comparison with conventional ultrasound, $\times$ ray studies, and ileocolonoscopy. Gut 2004; 53: $1652-1657$

[112] Parente F, Maconi G, Bollani S et al. Bowel ultrasound in assessment of Crohn's disease and detection of related small bowel strictures: a prospective comparative study versus $\times$ ray and intraoperative findings. Gut 2002; 50: 490 - 495

[113] Dignass A, Van AsscheG, Lindsay JO et al. European Crohn's and Colitis Organisation (ECCO). The second European evidence-based Consensus on the diagnosis and management of Crohn's disease: Current management. J Crohns Colitis 2010; 4: 28-62 
[114] Chen W, Lu CG, Lindsay JO et al. Smooth Muscle Hyperplasia/Hypertrophy is the Most Prominent Histological Change in Crohn's Fibrostenosing Bowel Strictures: A Semiquantitative Analysis by Using a Novel Histological Grading Scheme. J Crohns Colitis 2017; 11: 92 - 104

[115] Kratzer W, von Tirpitz C, Mason R et al. Contrast-enhanced power Doppler sonography of the intestinal wall in the differentiation of hypervascularized and hypovascularized intestinal obstructions in patients with Crohn's disease. J Ultrasound Med 2002; 21: 149-157

[116] Quaia E, de Paoli L, Stocca T et al. The value of small bowel wall contrast enhancement after Sulfur hexafluoride-filled microbubble injection to differentiate inflammatory from fibrotic strictures in patients with Crohn's disease. Ultrasound Med Biol 2012; 38: 1324-1332

[117] Schirin-Sokhan R, Winograd R, Tischendorf S et al. Assessment of inflammatory and fibrotic stenoses in patients with Crohn's disease using contrast-enhanced ultrasound and computerized algorithm: a pilot study. Digestion 2011; 83: $263-268$

[118] Lu C, Gui X, Chen W et al. Ultrasound Shear Wave and Contrast Enhancement: Effective Biomarkers in Crohn's Disease Strictures. Inflamm Bowel Dis 2017; 23: 421 - 430

[119] Braden B, Ignee A, Hocke $M$ et al. Diagnostic value and clinical utility of contrast enhanced ultrasound in intestinal diseases. Dig Liver Dis 2010; 42: $667-674$

[120] Baumgart DC, Müller HP, Grittner U et al. US-based Real-time Elastography for the Detection of Fibrotic Gut Tissue in Patients with Stricturing Crohn Disease. Radiology 2015; 275: 889-899

[121] Fraquelli M, Branchi F, Cribiù FM et al. The Role of Ultrasound Elasticity Imaging in Predicting lleal Fibrosis in Crohn'sDisease Patients. Inflamm Bowel Dis 2015; 21: $2605-2612$

[122] Dillman JR, Stidham RW, Higgins PD et al. Ultrasound shear wave elastography helps discriminate low-grade from high-grade bowel wall fibrosis in ex vivo human intestinal specimens. J Ultrasound Med 2014; 33: $2115-2123$

[123] Sconfienza LM, Cavallaro F, Colombi V et al. In-vivo Axial-strain Sonoelastography Helps Distinguish Acutely-inflamed from Fibrotic Terminal Ileum Strictures in Patients with Crohn's Disease: Preliminary Results. Ultrasound Med Biol 2016; 42: 855-863

[124] Di Mizio R, Maconi G, Romano S et al. Small bowel Crohn disease: sonographic features. Abdom Imaging 2004; 29: 23 - 35

[125] Hollerweger A. Colonic diseases: the value of US examination. Eur ] Radiol 2007; 64: 239-249

[126] Nylund K, Hausken T, Gilja OH. Ultrasound and inflammatory bowel disease. Ultrasound Q 2010; 26: 3-15

[127] Nylund K, Ødegaard S, Hausken T et al. Sonography of the small intestine. World J Gastroenterol 2009; 15: 1319-1330

[128] Maconi G, Radice E, Greco S et al. Bowel ultrasound in Crohn's disease. Best Pract Res Clin Gastroenterol 2006; 20: $93-112$

[129] Maconi G, Sampietro GM, Parente F et al. Contrast radiology, computed tomography and ultrasonography in detecting internal fistulas and intra-abdominal abscesses in Crohn's disease: a prospective comparative study. Am J Gastroenterol 2003; 98: 1545-1555

[130] Maconi G, Bollani S, Bianchi PorroG. Ultrasonographic detection of intestinal complications in Crohn's disease. Dig Dis Sci 1996; 41 : $1643-1648$

[131] Gasche C, Moser G, Turetschek K et al. Transabdominal bowel sonography for the detection of intestinal complications in Crohn's disease. Gut 1999; 44: $112-117$

[132] Martínez M], Ripollés T, Paredes JM et al. Assessment of the extension and the inflammatory activity in Crohn's disease: comparison of ultrasound and MRI. Abdom Imaging 2009; 34: 141 - 148

[133] Neye H, Ensberg D, Rauh P et al. Impact of high-resolution transabdominal ultrasound in the diagnosis of complications of Crohn's disease. Scand J Gastroenterol 2010; 45: 690-695
[134] Maconi G, Sampietro GM, Russo A et al. The vascularity of internal fistulae in Crohn's disease: an in vivo power Doppler ultrasonography assessment. Gut 2002; 50: 496-500

[135] Ripollés T, Martínez-Pérez MJ, Paredes JM et al. Contrast-enhanced ultrasound in the differentiation between phlegmon and abscess in Crohn's disease and other abdominal conditions. Eur J Radiol 2013; 82: e525-e531

[136] Cullen G, Vaughn B, Ahmed A et al. Abdominal phlegmons in Crohn's disease: outcomes following antitumor necrosis factor therapy. Inflamm Bowel Dis 2012; 18: 691-696

[137] Buisson A, Chevaux JB, Allen PB et al. Review article: the natural history of postoperative Crohn's disease recurrence. Aliment Pharmacol Ther 2012; 35: 625-633

[138] Gionchetti P, Dignass A, Danese S et al. ECCO. 3rd European Evidencebased Consensus on the Diagnosis and Management of Crohn's Disease 2016: Part 2: Surgical Management and Special Situations. J Crohns Colitis 2017; 11: 135-149

[139] Onali S, Calabrese E, Petruzziello C et al. Endoscopic vs ultrasonographic findings related to Crohn's disease recurrence: a prospective longitudinal study at 3 years. J Crohns Colitis 2010; 4: 319-328

[140] Calabrese E, Petruzziello C, Onali S et al. Severity of postoperative recurrence in Crohn's disease: correlation between endoscopic and sonographic findings. Inflamm Bowel Dis 2009; 15: 1635-1642

[141] Biancone L, Calabrese E, Petruzziello C et al. Wireless capsule endoscopy and small intestine contrast ultrasonography in recurrence of Crohn's disease. Inflamm Bowel Dis 2007; 13: 1256-1265

[142] Pallotta N, Giovannone M, Pezzotti P et al. Ultrasonographic detection and assessment of the severity of Crohn's disease recurrence after ileal resection. BMC Gastroenterol 2010; 10: 69

[143] Onali S, Calabrese E, Petruzziello C et al. Post-operative recurrence of Crohn's disease: A prospective study at 5 years. Dig Liver Dis 2016; 48: 489-494

[144] Paredes JM, Ripollés T, Cortés X et al. Non-invasive diagnosis and grading of postsurgical endoscopic recurrence in Crohn's disease: usefulness of abdominal ultrasonography and (99m)Tc-hexamethylpropylene amineoxime-labelled leucocyte scintigraphy. J Crohns Colitis 2010; 4: $537-545$

[145] Orlando A, Modesto I, Castiglione F et al. The role of calprotectin in predicting endoscopic post-surgical recurrence in asymptomatic Crohn's disease: a comparison with ultrasound. Eur Rev Med Pharmacol Sci 2006; 10: $17-22$

[146] Castiglione F, Bucci L, Pesce G et al. Oral contrast-enhanced sonography for the diagnosis and grading of postsurgical recurrence of Crohn's disease. Inflamm Bowel Dis 2008; 14: 1240-1245

[147] Parente F, Sampietro GM, Molteni M et al. Behaviour of the bowel wall during the first year after surgery is a strong predictor of symptomatic recurrence of Crohn's disease: a prospective study. Aliment Pharmacol Ther 2004; 20: $959-968$

[148] Maconi G, Sampietro GM, Cristaldi M et al. Preoperative characteristics and postoperative behavior of bowel wall on risk of recurrence after conservative surgery in Crohn's disease: a prospective study. Ann Surg 2001; 233: $345-352$

[149] Calabrese E, Zorzi F, Zuzzi S et al. Development of a numerical index quantitating small bowel damage as detected by ultrasonography in Crohn's disease. J Crohns Colitis 2012; 6: 852-860

[150] Zorzi F, Stasi E, Bevivino G et al. A sonographic lesion index for Crohn's disease helps monitor changes in transmural bowel damage during therapy. Clin Gastroenterol Hepatol 2014; 12: 2071 - 2077

[151] Danese S, Fiocchi C. Ulcerative colitis. N Engl ] Med 2011; 365: 1713 1725 
[152] Magro F, Gionchetti P, Eliakim R et al. Third European Evidence-Based Consensus on Diagnosis and Management of Ulcerative Colitis. Part 1: Definitions, diagnosis, extra-intestinal manifestations, pregnancy, cancer surveillance, surgery, and ileo-anal pouch disorders. J Crohns Colitis 2017; 11: 649-670

[153] Bru C, Sans M, Defelitto MM et al. Hydrocolonic sonography for evaluating inflammatory bowel disease. Am J Roentgenol 2001; 177: 99-105

[154] Strobel D, Goertz RS, Bernatik T. Diagnostics in inflammatory bowel disease: Ultrasound. World J Gastroenterol 2011; 17: 3192 -3197

[155] Antonelli E, Giuliano V, Casella G et al. Ultrasonographic assessment of colonic wall in moderate-severe ulcerative colitis: comparison with endoscopic findings. Dig Liver Dis 2011; 43: 703 - 706

[156] Parente F, Greco S, Molteni M et al. Role of early ultrasound in detecting inflammatory intestinal disorders and identifying their anatomical location within the bowel. Aliment Pharmacol Ther 2003; 18: 1009 1016

[157] Bremner AR, Griffiths M, Argent JD et al. Sonographic evaluation of inflammatory bowel disease: a prospective, blinded, comparative study. Pediatr Radiol 2006; 36: 947 - 953

[158] Civitelli F, Di Nardo G, Oliva S et al. Ultrasonography of the colon in pediatric ulcerative colitis: a prospective, blind, comparative study with colonoscopy. J Pediatr 2014; 165: 78-84

[159] Ruess L, Blask AR, Bulas DI et al. Inflammatory bowel disease in children and young adults: correlation of sonographic and clinical parameters during treatment. Am J Roentgenol 2000; 175: 79-84

[160] Arienti V, Campieri M, Boriani L et al. Management of severe ulcerative colitis with the help of high resolution ultrasonography. Am J Gastroenterol 1996; 91: 2163-2169

[161] Schwerk WB, Beckh K, Raith M. A prospective evaluation of high resolution sonography in the diagnosis of inflammatory bowel diasease. Eur J Gastroenterol Hepatol 1992; 4: 173-182

[162] Worlicek H, Lutz H, Heyder $\mathrm{N}$ et al. Ultrasound findings in Crohn's disease and ulcerative colitis: a prospective study. J Clin Ultrasound 1987; 15: $153-163$

[163] Maconi G, Ardizzone S, Parente F et al. Ultrasonography in the evaluation of extension, activity, and follow-up of ulcerative9 colitis. Scand J Gastroenterol 1999; 34: 1103-1107

[164] Parente F, Molteni M, Marino B et al. Are colonoscopy and bowel ultrasound useful for assessing response to short-term therapy and predicting disease outcome of moderate-to-severe forms of ulcerative colitis? a prospective study. Am J Gastroenterol 2010; 105: 1150-1157

[165] Haber HP, Busch A, Ziebach R et al. Ultrasonographic findings correspond to clinical, endoscopic, and histologic findings in inflammatory bowel disease and other enterocolitides. J Ultrasound Med 2002; 21: $375-382$

[166] Dixit R, Chowdhury V, Kumar N. Hydrocolonic sonography in the evaluation of colonic lesions. Abdom Imaging 1999; 24: 497 - 505

[167] Heyne R, Rickes S, Bock P et al. Non-invasive evaluation of activity in inflammatory bowel disease by power Doppler sonography. Z Gastroenterol 2002; 40: 171 - 175

[168] Bavil AS, Somi MH, Nemati M et al. Ultrasonographic evaluation of bowel wall thickness and intramural blood flow in ulcerative colitis. ISRN Gastroenterol 2012; 2012: 370495

[169] Parente F, Molteni M, Marino B et al. Bowel ultrasound and mucosal healing in ulcerative colitis. Dig Dis 2009; 27: 285-290

[170] Yoshida A, Kobayashi K, Ueno F et al. Possible role of early transabdominal ultrasound in patients undergoing cytapheresis for active ulcerative colitis. Intern Med 2011; 50: 11-15

[171] Socaciu M, Ciobanu L, Diaconu B et al. Non-Invasive Assessment of Inflammation and Treatment Response in Patients with Crohn's Disease and Ulcerative Colitis using Contrast-Enhanced Ultrasonography. Quantification. J Gastrointestin Liver Dis 2015; 24: 457-465
[172] Yamaguchi T, Yoshida S, Tanaka S et al. Predicting the clinical response to cytapheresis in steroid-refractory or dependent ulcerative colitis using contrast-enhanced ultrasonography. Scand J Gastroenterol 2009; 44: 831 - 837

[173] Rogoveanu I, Săftoiu A, Cazacu S et al. Color Doppler transabdominal ultrasonography for the assessment of the patients with inflammatory bowel disease during treatment. Rom J Gastroenterol 2003; 12: 277 281

[174] Girlich C, Schacherer D, Jung EM et al. Comparison between quantitative assessment of bowel wall vascularization by contrast-enhanced ultrasound and results of histopathological scoring in ulcerative colitis. Int J Colorectal Dis 2012; 27: 193-198

[175] Ishikawa D, Ando T, Watanabe O et al. Images of colonic real-time tissue sonoelastography correlate with those of colonoscopy and may predict response to therapy in patients with ulcerative colitis. BMC Gastroenterol 2011; 11: 29

[176] North American Society for Pediatric Gastroenterology, Hepatology, and Nutrition.; Colitis Foundation of America., Bousvaros A, Antonioli DA, Colletti RB, Dubinsky MC, Glickman JN, Gold BD, Griffiths AM, Jevon GP, Higuchi LM, Hyams JS, Kirschner BS, Kugathasan S, Baldassano RN, Russo PA. Differentiating ulcerative colitis from Crohn disease in children and young adults: report of a working group of the North American Society for Pediatric Gastroenterology, Hepatology, and Nutrition and the Crohn's and Colitis Foundation of America. J Pediatr Gastroenterol Nutr 2007; 44: 653-674

[177] Hirche TO, Russler J, Braden B et al. Sonographic detection of perihepatic lymphadenopathy is an indicator for primary sclerosing cholangitis in patients with inflammatory bowel disease. Int J Colorectal Dis 2004; 19: $586-594$

[178] Dietrich CF. Ultrasonography of the small and large intestine. In: Rose BD, (Ed) UpToDate. Wellesley MA, 2015

[179] Maconi G, Sampietro GM, Ardizzone S et al. Ultrasonographic detection of toxic megacolon in inflammatory bowel diseases. Dig Dis Sci 2004; 49: $138-142$

[180] de Barros N, Cerri GG, de Souza RochaM et al. Sonographic appearances of conglomerated polyps (giant polyposis) in patients with Crohn's disease. J Clin Ultrasound 2000; 28: 199-205

[181] Maconi G, Bolzacchini E, Dell'Era A et al. Portal vein thrombosis in inflammatory bowel diseases: a single-center case series. J Crohns Colitis 2012; 6: 362-367

[182] Landman C, Nahon S, Cosnes J et al. Portomesenteric vein thrombosis in patients with inflammatory bowel disease. Inflamm Bowel Dis 2013; 19: $582-589$

[183] Ziech ML, Hummel TZ, Smets AM et al. Accuracy of abdominal ultrasound and MRI for detection of Crohn disease and ulcerative colitis in children. Pediatr Radiol 2014; 44: 1370-1378

[184] Pera A, Cammarota T, Comino E et al. Ultrasonography in the detection of Crohn's disease and in the differential diagnosis of inflammatory bowel disease. Digestion 1988; 41: 180-184

[185] Hata J, Haruma K, Suenaga K et al. Ultrasonographic assessment of inflammatory bowel disease. Am J Gastroenterol 1992; 87: 443-447

[186] Valette PJ, Rioux M, Pilleul F et al. Ultrasonography of chronic inflammatory bowel diseases. Eur Radiol 2001; 11: 1859-1866

[187] Puylaert JB, Lalisang RI, van der Werf SD et al. Campylobacter ileocolitis mimicking acute appendicitis: differentiation with graded-compression US. Radiology 1988; 166: 737-740

[188] Puylaert JB, Van der Zant FM, Mutsaers JA. Infectious ileocecitis caused by Yersinia, Campylobacter, and Salmonella: clinical, radiological and US findings. Eur Radiol 1997; 7: 3-9

[189] Ros PR, Buetow PC, Pantograg-Brown L et al. Pseudomembranous colitis. Radiology 1996; 198: 1-9

[190] Kedar RP, Shah PP, Shivde RS et al. Sonographic findings in gastrointestinal and peritoneal tuberculosis. Clin Radiol 1994; 49: 24-29 
[191] Mathis G, Metzler ]. Sonography in salmonella enterocolitis. Ultraschall in Med 1992; 13: $106-109$

[192] Siegel MJ, Friedland JA, Hildebolt CF. Bowel wall thickening in children: differentiation with US. Radiology 1997; 203: 631-635

[193] Lim JH, Ko YT, Lee DH et al. Sonography of inflammatory bowel disease: findings and value in differential diagnosis. Am J Roentgenol 1994; 163: $343-347$

[194] Dietrich CF, Lembcke B, Jenssen C et al. Intestinal ultrasound in rare gastrointestinal diseases, update, part 1. Ultraschall in Med 2014; 35 : $400-421$

[195] Ripollés T, Simó L, Martínez-Pérez MJ et al. Sonographic findings in ischemic colitis in 58 patients. Am J Roentgenol 2005; 184: 777 - 785
[196] Nuernberg D, Ignee A, Dietrich CF. Current status of ultrasound in gastroenterology-bowel and upper gastrointestinal tract-part 2. Z Gastroenterol 2008; 46: 355 - 366

[197] Aideyan UO, Smith WL. Inflammatory bowel disease in children. Radiol Clin North Am 1996; 34: 885-902

[198] O'Malley ME, Wilson SR. US of gastrointestinal tract abnormalities with CT correlation. Radiographics 2003; 23: 59-72

[199] Truong M, Atri M, Bret PM et al. Sonographic appearance of benign and malignant conditions of the colon. Am J Roentgenol 1998; 170: 1451 1455 